\title{
Association between parental involvement and academic achievement of deaf children at Mulago school for the deaf, Kampala, Uganda
}

\author{
Josephine Akellot ${ }^{1}$, Paul Bangirana ${ }^{2}$
}

1. Department of Mental Health and Community Psychology, Makerere University, Kampala, Uganda.

2. Department of Psychiatry, Makerere University, Kampala, Uganda.

\begin{abstract} and academic achievement.

DOI: https://dx.doi.org/10.4314/ahs.v19i2.53

Background: There is considerable evidence showing the benefits of parental involvement in school activities and how this influences the academic performance of deaf students in high and middle income countries. ${ }^{1-3}$ In Uganda, few studies and reports indicate ways in which parents are involved in their children's activities but no specific study has focused on how parents' involvement may affect attainment of academic skills necessary for learning among deaf children except for the advocacy of deafness as a disability and reporting on their education in general terms. ${ }^{4-8}$
\end{abstract}

Background: Deaf children face many challenges in dealing with educational opportunities and ensuring attainment of academic skills. A parent's involvement in the child's education has the potential to enhance academic performance. We sought to study the association between parental involvement and academic achievement among deaf children in Uganda.

Methods: Using purposive consecutive sampling, one hundred and eight parents of deaf children (Primary 1 to 7) were recruited from Mulago School for the Deaf in Kampala, Uganda. The Parental Involvement Questionnaire was used to measure parents' involvement in school activities while the Wide Range Assessment Test, third edition, was used to measure academic achievement (reading, spelling and arithmetic). Linear regression was used to test the association between parental involvement

Results: One hundred and five children with mean age 11.09 years (SD $=2.89)$ were enrolled of whom $56(35.3 \%)$ were female. With a Beta coefficient of 0.07 , a $7 \%$ unit increase of summed parental involvement showed no significant association between parental involvement and academic achievement $(\mathrm{p}=0.46)$ of the deaf children.

Conclusion: Parental involvement was not associated with academic achievement among deaf children in Kampala. Other factors associated with academic achievement need to be identified to enhance deaf children's performance at school.

Keywords: Parental involvement, academic achievement, deaf children, Mulago school for the deaf, Kampala, Uganda.

Cite as: Akellot J, Bangirana P. Association between parental involvement and academic achievement of deaf children at Mulago deaf school, Kampala, Uganda. Afri Health Sci.2019;19(2): 2270-2281. https:// dx.doi.org/10.4314/ahs.v19i2.53

\section{Corresponding author:}

Josephine Akellot,

Department of Mental Health

and Community Psychology,

Makerere University,

P.O. Box 7062 Kampala, Uganda.

Phone: +256772619334

Email: josocama@gmail.com
In Uganda, about $13 \%$ of children are disabled and 23.1\% of these have a hearing disability. ${ }^{9}$ 'The National Development Plan of Uganda 2011-2015 indicated that 10\% of children have special needs. ${ }^{10}$ The situational analysis of children with disability indicated that only $9 \%$ of the disabled children attend primary schools compared to the $6 \%$ continue to the secondary school level against the national average of $25 \%$. Furthermore, among all children with disabilities, those with hearing disability have the highest enrolment in school of $29 \%$ albeit low completion rate. ${ }^{9}$

Many factors affect the attainment of academic skills among deaf children. These factors include individual personal capabilities, syllabi coverage and teaching methods. ${ }^{11,12}$ Policies, however, provide for special needs education for the deaf children but parents are not aware of the effects of their involvement in school programs and how these may influence attainment of academic skills necessary for success. ${ }^{9,13,14}$ To contextualize environmennational average of $92 \%$ and of the deaf children only

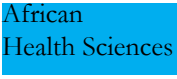

(C) 2019 Akellot et al. Licensee African Health Sciences. This is an Open Access article distributed under the terms of the Creative commons Attribution License (https://creativecommons.org/licenses/BY/4.0), which permits unrestricted use, distribution, and reproduction in any medium, provided the original work is properly cited. 
tal effects, deafness is not merely a disability one "suffers" from but it is a multi-faceted and vast physical, social and psychological phenomena which affects the child's growth, development and wellbeing. ${ }^{15,16}$ Expectedly, parents especially mothers are highly involved during the early stages of the child's development hence enabling their ability to notice when a child fails to respond to environmental cues like noise. ${ }^{17-19}$ This could be regarded as a social functioning and problem behavior but it ignites the search for confirmatory answers especially from the health workers. ${ }^{20,21}$ Without distinguishing the different parenting effects on development, early childhood development, like poor cognitive development, profoundly affect academic outcomes. ${ }^{16,17,22}$ As such, we need to retrospectively acknowledge effects of the deaf children prior to school age when we are looking at the academic skills attainment. Before parents identify the schools for their hearing impaired children, they will have noticed earlier between 0 to 3 years that the child had a hearing impairment either as one that is congenital or acquired ${ }^{14}$. Historically, deaf children have consistently lagged behind academically and socially at all levels. ${ }^{16,22,23}$ Poor performance in reading, spelling and arithmetic skills are common among deaf children but the associated factors are unknown in Uganda. ${ }^{17}$ Scholars elsewhere reported factors associated with poor performance as parents' socio-economic and education level, inadequacies in "learning resources and monitoring for teachers by head teachers, understaffing, high teacher turnover rate, inadequate prior preparation, large workload, absenteeism by both teachers and pupils, pupils lateness, lack of support from parents" while others attributed poor performance to "teachers who do not have both the academic and the professional teacher qualification but also teachers who are academically and professionally qualified, but work under unfavorable conditions of service and are less dedicated to work", as well as lack of supervision and motivation. ${ }^{24-26}$

Basing on yearly primary leaving examination results in Uganda, performance of deaf children has been low, implying that academic skills effective for learning were not achieved. ${ }^{27}$ Hypothetically, parents' participation and application of school, family and community partnership approaches in a deaf child's education program and development are very necessary in academic skills attainment. These approaches, however, are rarely implement- ed in Uganda hence the deaf children have struggled to meet their personal or academic goals within all levels of education on their own. ${ }^{28}$ Despite the guidelines by the Ministry of Education stating that parents should take keen interest and get more involved in their children's learning to improve the quality of education, parents' involvement in school programs has majorly been through participating in the construction of schools by contributing bricks, tiles, fetching water, roofing buildings or finishing the schools on top of providing education materials and paying fees, attending meetings and reading circulars. ${ }^{29}$ Seemingly, these may be viewed as aspects of parental involvement which are 'external' to academic skills attainment. ${ }^{6}$

However, literature showed that parental involvement was greatly associated with academic skills attainment. ${ }^{30-33}$ Other scholars pointed out that the effects of parental involvement on academic skills attainment balanced out because of iterative outplay of child, family and school facilitators and detractors. ${ }^{31}$

In spite of the positive evidence, deaf children still have challenges in academics. Such challenges are ecological in nature with an interactive force from the individual child's own learning attitudes, beliefs, assumptions, resilience, and level of stimulation to environmental dictates like family level of support and involvement, ${ }^{33,43}$ institutional educational system barriers like lack of remedial and educational programs, insufficient teachers, unequipped schools, and a lack of instructional and assessment tools

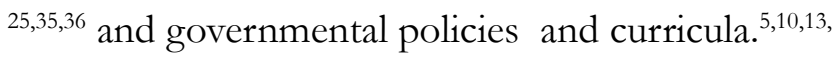

Basing on the hypothesis that parental involvement does affect academic skills attainment, we sought to examine the association between parental involvement and academic skills of deaf children at Mulago School for the Deaf in Kampala, Uganda.

\section{Methods:}

We conducted a cross-sectional study at Mulago School for the Deaf in Kampala, Uganda in the months of February 2014, the time when pupils report for the beginning of the year. This is one of the two schools for deaf children located in Kampala. As a special needs school, it admits only deaf children in Primary one to seven. During the study period, a total of 108 children had reported for the beginning of the term. We recruited all except 3, who were above 15 years (an upper limit age for this study). 
Parents were interviewed using the Parental Involvement Questionnaire (modified Eptein's framework). ${ }^{30}$ Two weeks later, the children whose parents consented were assented and assessed using the Wide Range Assessment Test, Third Edition (WRAT-3) for academic achievement. ${ }^{37}$ The tools are described below.

\section{Instruments}

\section{Parental Involvement}

Parental involvement in a child's school program was measured using Epstein's framework for six types of involvement (modified with permission). ${ }^{30}$ Permission was granted by Dr Joyce Epstein to translate or adapt the questions to fit our research questions about family involvement in Uganda. Specifically, we requested for permission to simplify the English language where necessary to fit the study population i.e. parents and guardians of the deaf children; the majority of whom had elementary knowledge of English. This was validated in the U.S ${ }^{29,38,39}$ and it has been used in Ghana ${ }^{40}$ Phillipines $^{41}$ and Uganda. ${ }^{4}$ The tool had positive construct validity in Ghana, internal validity in both Uganda and Phillipines. The reliability of these studies was based on the consistency of the questions and items used but could have been affected by social factors and interpretations.

However, in our study, the questionnaire had seven domains that included demographic factors of the participant and the six types of Epstein's parental involvement that is, parenting, communication, volunteerism, decision making, learning and collaboration with the community. Part A measured demographic factors while Part B measured type 1 involvement of parenting which entailed using a 5 point likert scale of 'not interested' to 'extremely interested' to answer 11 questions. Part B aimed at determining whether all families helped to establish home environments to support deaf children as students. Part $\mathrm{C}$ measured type 2 involvement of communication using a 7 point likert scale of 'Not effective at all' to 'not available' to answer 5 questions. This was aimed at determining whether there are effective forms of school-tohome and home-to-school communication about school programs.

Part D measured type 3 involvement of volunteering. This part had a section that addressed volunteer experiences and used a 3 point Likert scale of 'yes' to 'not applicable' to answer 8 questions for activities they volunteered in while the last section of part D used 'specify' to answer the last question. Part D was meant to establish whether schools could recruit and organize parents' help and support in school programs. Part E measured type 4 learning at home to provide information and ideas to families about how to help students at home with homework and other curriculum-related activities, decisions and planning using a 6 point Likert scale of 'never' to 'not applicable' to answer 5 questions and it also used 'specify' to answer the last section. Part F measured type 5 of parental involvement which was decision-making using a 3 point Likert scale of 'yes' to 'unsure' to answer 10 questions. This fifth part established whether to include parents in school decisions, developing parent leaders and representatives. Part $G$ measured type 6 of parental involvement in collaboration with the community to identify and integrate resources and services from the community to strengthen school programs, family practices and student learning and development using a 3 point Likert scale of 'yes' to 'unsure' to answer 5 questions. The total number of items was 29 and the highest score indicated the more parental involvement and vice versa. This instrument was administered to both parents and children. All these sections were maintained but language and class reference were adjusted to fit lay vocabulary and Ugandan school grading system (i.e. nursery and primary).

The internal consistency for the different sub-scales were calculated using the Cronbach alpha, $\alpha$, which ranged from .55 to $.69(\alpha=.69, .61, .63, .55, .69 \& .66$ for parenting, communication, volunteerism, decision making and collaboration with community respectively). Other than volunteerism, the rest were within the range of .59 and .77 used for the deaf populations and the calculated reliability $0 f \alpha=.67 .^{42}$ Content and internal validities were based on the use of the same questionnaire photocopied and read or signed out by the sign language teachers in the presence of the researcher. The latter followed by listening to read aloud version of the questions.

\section{Academic skills \\ Wide Range Assessment Test -3}

The Wide Range Achievement Test (Third Edition (WRAT-3) ${ }^{38}$ was used to measure academic skills; reading, spelling, and arithmetic (math computation). ${ }^{37}$ The 
spelling sub-test required the subject to spell letters and 40 words from dictation and the arithmetic test involved counting, reading number symbols, solving oral problems, and performing written computations. Reading sub-test assessed an individual's ability to recognize and name 15 letters and pronounce 42 words out of context. Reading, spelling and arithmetic were administered using sign language and tested against the reading materials familiar to the deaf children as per the school curriculum like the alphabet, English grammar and mathematics.

Procedurally, during testing, the WRAT-3 was given to the sign language teachers who randomly picked half of the questions from the WRAT-3 which were similar in English grammar and math computation to what the pupils knew and administered as a class test. Alphabetically, the works and numbers used in the scale were the $A$ to $Z$ of the alphabet and 0 to 9 of the number line. The questions were signed out to the pupils and the latter wrote down the answer. These were marked using the standard answers of the WRAT-3. Using Pearson correlation coefficient, the association between the WRAT-3 and class test Spelling, Arithmetic and Reading scores had weak positive relationships of $\mathrm{R}=0.07,0.10$ and 0.08 with $\mathrm{p}$-values of $0.507,0.311$ and 0.409 respectively. Overall, WRAT3 and class test academic skills (Spelling, Arithmetic \& Reading) had a weak positive relationship of $\mathrm{R}=0.067$, $\mathrm{p}=0.49$.

Contextually, WRAT-3 was earlier on used in Ugandan children to measure academic skills of reading, spelling, and math computation. ${ }^{43,44}$ In these hearing and talking children, for the spelling sub-test, the 40 words were dictated rather than signed while for the arithmetic test, talking children counted, read number symbols aloud and solved mathematical problems orally as the deaf children signed. However, they both performed written computations. In the reading sub-test, both groups of children were assessed on the individual's ability to recognize and name 15 letters. The difference between the two groups was that the talking and hearing children pronounced 42 words while the deaf children signed same words.

In comparison, the median test coefficient alphas for WRAT-3 ranged from .85 to $.95 .{ }^{37}$ In the hearing children population, alternate form correlations of reading (.92), spelling (.93), and Arithmetic (.93) supported the reliability of the measure. ${ }^{45}$ However, reliability and validity of the WRAT-3 among the deaf population had not been documented nor had been standardized in this population. So reading, spelling and arithmetic skills were only measured using the reading materials used and familiar to the deaf children as per the school curriculum and the set test from the WRAT-3.

\section{Statistical analysis}

Having had parental involvement as a single explanatory variable with normally distributed answers, a linear regression was run to determine the predictors of how parental involvement (independent variable) affects academic skills (dependent variable) and the significance of these predictors. A linear regression was run at a $95 \%$ confidence level with an error term of \pm 3 using SPSS (Statistical Package for Social Scientists) version 16.0. The researcher who did not know sign language worked with sign language teachers to ensure consistency and reduce bias. The teachers read out questions aloud as they signed them for the students and verbatim relayed answers aloud so that the researcher followed as students gave them.

\section{Ethical considerations}

This study was approved by the Institutional Review Board of the College of Humanities and Social Sciences, Makerere University an affiliate of the Uganda National Council of Science and Technology (IRB Number UGREC-021). Written informed consent was sought from the parents while assent was obtained from children aged 7 years and older.

\section{Results:}

\section{Socio demographic characteristics}

During the study period, 105 deaf children with the mean age of 11.09 (SD =2.89) participated. More girls $56(53.3 \%)$ than boys participated in the study. Majority of the pupils, $67(63.8 \%)$ resided in urban centers. The class representation varied with lower primary (Primary 1 to Primary 4) contributing $66(62.9 \%)$ participants, of whom $13(12.3 \%)$ were in Primary 1. Most of the children $66(53.1 \%)$ were separated from either or both of their parents during their lives (Table 1). 
Table 1: Socio demographic factors of Deaf Children attending Mulago School for the Deaf

\begin{tabular}{|c|c|c|c|c|}
\hline \multicolumn{2}{|l|}{ Characteristic } & \multicolumn{2}{|c|}{$\mathrm{N}(\%)$} & \multirow[t]{2}{*}{$\mathrm{M}(\mathrm{SD})$} \\
\hline Gender (female) & & 56 & $(53.3)$ & \\
\hline Age (years) & & & & $11.09(2.89)^{1}$ \\
\hline Residence (Urban) & & 67 & $(63.8)$ & \\
\hline \multirow[t]{3}{*}{ Religion } & Catholic & 42 & $(40.0)$ & \\
\hline & Anglican & 28 & $(26.7)$ & \\
\hline & Others & 35 & $(34.3)$ & \\
\hline \multirow[t]{3}{*}{ Tribe } & Baganda & 50 & $(56.2)$ & \\
\hline & Basoga & 11 & $(10.5)$ & \\
\hline & Others & 35 & $(33.3)$ & \\
\hline \multirow[t]{3}{*}{ Class $^{1}$} & Primary One & 21 & $(20.0)$ & \\
\hline & Primary Two & 19 & $(18.1)$ & \\
\hline & Others & 65 & $(61.8)$ & \\
\hline \multirow[t]{3}{*}{ Family type } & Two parent & 58 & $(55.2)$ & \\
\hline & One dead & 33 & (31.4) & \\
\hline & Others & 14 & (3.4) & \\
\hline \multirow[t]{3}{*}{ Brought up by } & Parents & 85 & $(81.7)$ & \\
\hline & Relatives & 15 & $(14.4)$ & \\
\hline & Others & \multicolumn{2}{|c|}{$4(3.9)$} & \\
\hline
\end{tabular}

Majority of parents/guardians 77 (73.3\%) were female. Slightly, more than half of them $55(52.4 \%)$ were unemployed, $22(21 \%)$ were peasants engaged in subsistence farming and of these,28 (27\%) were self-employed in commercial business. Seventy five percent (78) of parents and guardians earned $\leq 100,000$ Uganda shillings $(\leq$ $\$ 30)$. Over half $65(61.9 \%)$ of the parents/guardians were married, 24 (22.8\%) were separated, 1(1\%) were divorced and $15(14.3 \%)$ were widowed. Majority, 53(50.5\%) of the parents/guardians had stopped at primary level of education with $34(32.5 \%)$ having stopped at secondary level and $15(15.2 \%)$ having had tertiary education while only $6(5.7 \%)$ had ever attained university education as indicated in table 2. 
Table 2. Socio demographic factors of Parents and guardians of the Deaf Children attending Mulago school for the Deaf.

$\left.\begin{array}{llll}\hline \text { Characteristic } & & \mathbf{N}(\%) \\ \hline \text { Sex (female) } & & 77 \quad(73.3) \\ \text { Occupation (unemployed) } & & 55 \quad(52.4) \\ \text { Income per month (UGSH) } & \geq 300,000 & 7(6.73) \\ & \text { Between 200,000-300,000 } & 19 & (18.27) \\ & \leq 100,000 & 78 & (75.00) \\ \text { Marital status } & \text { Married } & 65 & (61.9) \\ & \text { Separated/divorced } & 24 & (22.9) \\ & \text { Widowed } & 1(15.2) \\ \text { Parent's life status } & \text { Both alive } & 70 & (66.7) \\ & \text { One dead } & 17 & (16.2) \\ \text { Disabled children } & \text { Others } & 18 & (17.1) \\ \text { Education } & \text { Yes } & 3(2.9) \\ & \text { No } & 102(97.1) \\ & \text { Primary } & 53 & (50.5) \\ & \text { Secondary } & 34 & (32.4) \\ & \text { Others } & 18 & (17.1)\end{array}\right]$

Prior to running the regression analysis, we controlled for variables that could affect the outcome. The gender, age and class of the children and gender, occupation and socio-economic status of the parents were identified as variables that would affect the outcome of the bivariate tests between academic skills and parental involvement. After running the bivariate analysis of each of the social demographics with academic skills, only the age and class of the children were significant $(\mathrm{P}<0.05)$ hence they were controlled in the regression analysis.

Summed parental involvement also had different effects on the academic skills. A unit increase in the summed parental involvement led to $8 \%$ and $17 \%$ increase in spelling and reading skills and to a $10 \%$ decrease in arithmetic skills. Overall, a unit increase in a summed parental involvement led to a $7 \%$ increase in summed up academic skills with an insignificant relationship ( $\mathrm{p}>0.05)$.

The different forms of parental involvement (helping, communication, volunteerism, decision making, learning and collaboration with community) had different effects on academic skills development. Five of the involvement types had insignificant relationship with academic skills $(\mathrm{P}>0.05)$ except volunteering which had a significant relationship with arithmetic skills $(\mathrm{P}<0.05)$. Using Beta values, a unit increase in parents' involvement through helping, volunteering, learning and decision making led to a positive increase in spelling, arithmetic and reading skills attainment. However, a unit increase in parents' communication and community collaboration led to a decrease in spelling and reading. In a summative form, parental involvement also had different effects on the academic skills. A unit increase in the summed parental involvement led to $8 \%$ and $17 \%$ increase in spelling and reading skills and to a $10 \%$ decrease in arithmetic skills. Overall, a unit increase in a summed parental involvement led to a $7 \%$ increase in academic skills with an insignificant relationship $(\mathrm{p}=.46)$ as indicated in Table 3. 
Table 3. Association between parental involvement (spelling, arithmetic and reading) and academic achievement

\begin{tabular}{|c|c|c|c|c|c|c|}
\hline & \multicolumn{3}{|l|}{$\mathrm{B}(n=10$} & \multicolumn{3}{|c|}{$\mathrm{B}(n=10$} \\
\hline & 5) & $p$-val & $\mathrm{B}(n=105)$ & $p$-val & 5) & $p$-val \\
\hline Helping & 0.13 & 0.72 & 0.16 & 0.65 & 0.04 & 0.90 \\
\hline Communication & -0.18 & 0.35 & 0.07 & 0.70 & -0.03 & 0.87 \\
\hline volunteering & 0.14 & 0.29 & 0.26 & 0.05 & 0.16 & 0.20 \\
\hline Decision making & 0.15 & 0.23 & 0.09 & 0.44 & 0.18 & 0.13 \\
\hline Community collaboration & 0.03 & 0.81 & 0.10 & 0.40 & -0.01 & 0.91 \\
\hline Learning & 0.04 & 0.86 & 0.10 & 0.69 & 0.03 & 0.90 \\
\hline \multicolumn{7}{|c|}{ Association Overall academic skills and general parental involvement } \\
\hline & $\mathrm{B}(n=10$ & \multicolumn{5}{|c|}{$P(n=105)$} \\
\hline & 5) & & & & & \\
\hline Spelling & 0.08 & \multicolumn{5}{|l|}{0.4} \\
\hline Arithmetic & -0.1 & \multicolumn{5}{|l|}{0.32} \\
\hline Reading & 0.17 & \multicolumn{5}{|l|}{0.08} \\
\hline Summed Academic Skills & 0.07 & \multicolumn{5}{|l|}{0.46} \\
\hline
\end{tabular}

\section{Discussion}

This study undertaken amongst deaf children sought to establish the association between parental involvement and academic skills of deaf children in Uganda. The study established that there was no relationship between parental involvement and academic skills of the deaf children. From these findings, parental involvement in a summative form does not influence academic skills. This is because the six types of parental involvement have different effects they contribute in the deaf child's education lifetime and learning abilities. Ultimately, this is in support of Epstein's framework which suggested that the six types of parental involvement contribute differently to academic skills. In line with Toscano et al's conclusion that academic skills depended on child's own experiences, traits, habits, attitude, personality and emotional development. ${ }^{30,46}$

The study results are in agreement with this conclusion because deaf children also have individual abilities in learning that do not depend entirely on external factors like parents' help in homework or any of the other five types of parental involvement but rather internal capabilities and strength. Contrary to this agreement, evidence showed that parental involvement helped to reduce anxiety for mathematics and that parental involvement was 'a significant positive predictor of early reading skills development. ${ }^{37}$ Although this prediction would not be considered an association with academic skills, it was indicative of how parental involvement in the deaf child's education program could strongly contribute to academic performance. ${ }^{1,47}$ In our context, positivity without quality would mean nothing as was shown in our findings that parental involvement through helping, volunteering, learning and decision making insignificantly led to a minimal increase in spelling, arithmetic and reading scores. ${ }^{1}$ Likewise, as shown in figure 1 of our results, the fifty eight (55\%) deaf children categorised as preschool using the WRAT3 grading, did not have high scores in performance on reading, spelling and arithmetic even if majority were in upper primary (P.4-P.7) and were aged eight years and above. ${ }^{23}$ This category of children had spent more time in school and would have been socially adapted to the environment with or without parental involvement. Given these factors, without much attention being attached to the effects of parental involvement, learning would have taken place that could result into a higher unit increase in reading, spelling and arithmetic skills. 


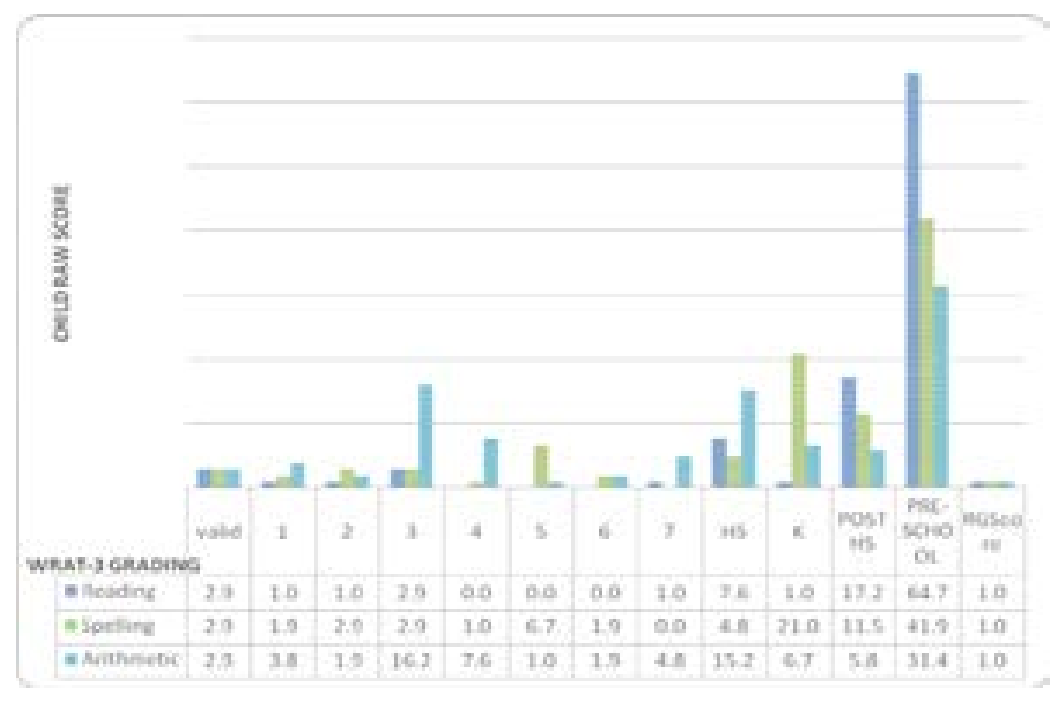

Fig 1: showing the distribution of the children's raw scores against the WRAT-3 grading scale.

These arguments are supported by the theory of social learning in which Bandura pointed out that human learning in a social environment was affected by the environment and cognitive abilities of the individual. ${ }^{48}$ Undoubtedly, parental involvement is an environmental factor although human behavior like learning is highly determined by the reciprocal interaction between the environment and the learner. ${ }^{49}$ From our study, the results showed that most parents were not highly educated and struggled economically as most earned below 100,000 thousand shillings (26 USD) monthly. This low status in education and economic hardship negatively impacts the ability, strength and quality of parental involvement in the child's academic skills learning

From the system's theory of input and output, a deaf child learns from social organizations that connect with $\mathrm{him} /$ her and with each other. When the deaf child's systems input, for example the teacher's input in teaching academic skills, do not balance the output such as the academic skills learning then achievement and performance are bound to be affected. ${ }^{50}$ In trying to create the equilibrium state, the schools for the deaf provide learning environment whereby the teachers contribute virtual parental support that leads to attaining academic skills. ${ }^{49,50}$

This result disagrees with Kelly et al. who found that poor academic skills are due to poor parental involvement. ${ }^{51}$ Likewise, Berg and Noort's study in Eastern Uganda suggested that socio-demographic factors like parents' level of education, low income, rural residence, and means of communication with the schools were associated with academic skills attainment rather than parental involvement. ${ }^{4}$ Although this study would have agreed with Berg and Noort's study that outlined socio-demographic factors, it is noteworthy that despite both studies being conducted among pupils in primary schools in Uganda, the study regional locations, settings and populations were different despite using semi structured questionnaire with the same properties as parental involvement questionnaire developed on the basis of Epstein's theory on parental involvement. ${ }^{52}$ For this study, we viewed parental involvement in a summed form and did not correlate academic skills and the socio demographics. Due to the subtle types of parental involvement, as defined by the relationship between these constructs and academic skills in Epstein's framework for six types of involvement, each should be individually examined. ${ }^{52}$ Although, in our study, we regressed the individual types of involvement with the academic skills, there was however no significant relation of all the different six types' involvement as well as the summed up parental involvement except for volunteerism and arithmetic skills. It can therefore be argued that parental involvement in a summative form does not have a relationship with academic skills because many aspects of involvement overlap and are not spelled out like the specific types of parenting involvement to which Epstein alludes. ${ }^{52}$ This argument supports this study's findings that parental involvement is not associated with academic skills which provides a prediction that other factors may be playing more significant roles. Externally, according to 
the economic, social and cultural rights report in Uganda some of these factors are teacher-focused such as inadequate sign language training, low motivation and absenteeism while others are child-focused ${ }^{10}$. Achievement at any level of child's education assessment is based on English and comprehension fluency. Deaf children join school at different times of their development with different skills in sign language. Fluency in English is highly influenced by the mother tongue to which the deaf children may not have mastered because family members do not use sign language. ${ }^{13}$ When they join school, mode of classroom communication, curriculum content coverage and level of literacy are compounding factors that also influence academic achievement and negatively impact on language and communication. ${ }^{23,53,54}$ This means that academic achievement starts at an early stage and is facilitated by a number of factors in the environment that reciprocate each other to a large extent. For this reason, even if parents had negative views about school programs or were not involved in any way, the academic skills attainment would not be affected and the effects would reduce over time. Even with results showing positive and negative effects from the different six types of parental involvement, no significant effect resulted from the summed parental involvement on academic skills.

It is relevant to note that deafness as a disability does not affect academic skills attainment. ${ }^{35}$ In this study, parental involvement in a summative form does not also explain the gaps in academic skills attainment. ${ }^{29,41}$ The results showed interplay between the effects of academic skills and parental involvement as a predictor of insignificant increase or decrease, but did not explain how the academic skills attainment was achieved. This prediction of a decreased unit effect of parental involvement on spelling and reading and an increased unit effect on arithmetic however, is in line with the fact that it is essential for parents to focus on, contribute to and be involved in the school programs with emphasis on helping with homework, communicating with school, participating in decision making and learning process of the children and collaborating with the community while strengthening the spirit of volunteerism as it positively increased effects on arithmetic. Parental involvement also is necessary in facilitating social learning because these deaf children learn a lot through observation. ${ }^{52,53}$

The study was limited by the choice of scales used to measure academic skills and parental involvement. The scales adopted for this study are not standardised for deaf children hence the true performance was difficult to assess (reliability and validity among the deaf population had not been documented). It was also difficult to establish the truth from the respondents (the pupils may not have been conversant with some of the aspects being assessed in the tool and the parents may have wanted to give information that portrayed involvement in instances when it was otherwise) and finally, the study was carried out at a single centre and it was also limited by the small sample size.

\section{Conclusion}

The finding of this study carried out in a school for the deaf found no association between parental involvement and academic skills achievement of the deaf children. We recommend larger studies looking at other factors that could explain the poor performance of these children.

\section{Acknowledgments}

First of all, we would like to thank the parents and deaf children who participated in this project. We thank Joyce Epstein for her contributions to development of the parental involvement Questionnaire.

The study was supported by Training Health Researchers into Vocational Excellence in East Africa (THRiVE), grant number 087540 funded by the Wellcome Trust. The contents of this article are solely the responsibility of the authors and do not necessarily represent the official views of the supporting offices.

Paul Bangirana was a NURTURE fellow under NIH grant D43TW010132 during this study.

\section{Conflict of interest}

None to declare.

\section{References}

1. Calderon R. Parental Involvement in Deaf Children's Education Programs as a Predictor of Child's Language, Early Reading, and Social-Emotional Development. J Deaf Stud Deaf Educ. 2000;5(2):140-155. doi:10.1093/ deafed/5.2.140.

2. Cole M. The Importance of Parental Involvement in Language Acquisition and Activities and Techniques to Enhance the Home-School Connection.; 2008. http:// digitalcommons.wustl.edu/pacs_capstoneshttp://digi- 
talcommons.wustl.edu/pacs_capstones/347. Accessed October 4, 2018.

3. Dalun Zhang D, Hsu H-Y, Kwok O, Benz M, Bowman-Perrott L. The Impact of Basic-Level Parent Engagements on Student Achievement: Patterns Associated with Race/Ethnicity and Socioeconomic Status (SES). J Disabil Policy Stud. 2011;22(1):28-39. doi:10.1177/1044207310394447.

4. Berg R, Noort L. Parental Involvement in Primary Education in Uganda. 2011.

5. Ministry of Education Uganda. The Development of Education in Uganda in the Last Ten Years. Geneva; 2001. http://www.ibe.unesco.org/International/ICE/ natrap/Uganda.pdf. Accessed October 4, 2018.

6. UNESCO. Education For All Global Monitoring Report 2011: The hidden crisis: Armed conflict and education - World | ReliefWeb. https://reliefweb.int/report/ world/education-all-global-monitoring-report-2011-hidden-crisis-armed-conflict-and-education. Published 2011. Accessed October 4, 2018.

7. ActionAidUSA. Hearing Impaired Students in Uganda. 8. DFID. DFID Guide Notes: Education for Children with Disabilities-Improving Access and Quality.; 2011. https://assets.publishing.service.gov.uk/government/ uploads/system/uploads/attachment_data/file/67664/ edu-chi-disabil-guid-note.pdf. Accessed October 4, 2018. 9. UNICEF. Situation Analysis on the Rights of Children with Disability in Uganda.; 2014. https://www.unicef. org/uganda/UNICEF_CwD_situational_analysis_FINAL.pdf. Accessed October 4, 2018.

10. Government of Uganda. National Development Plan: 2010-2015.; 2010. http://npa.ug/wp-content/themes/ npatheme/documents/NDP2.pdf. Accessed October 4, 2018.

11. Albertini JA, Kelly RR, Matchett MK. Personal Factors That Influence Deaf College Students' Academic Success. J Deaf Stud Deaf Educ. 2012;17(1):85-101. doi:10.1093/deafed/enr016.

12. Maina E, Oracha P, Indoshi F. Curriculum factors influencing performance of deaf students in mathematics. Int Res J. 2011;(2):956-964. http://www.internationalresearchjournals.org/er/march-2011-vol-2-issue-3/ curriculum-factors-influencing-performance-of-deaf-students-in-mathematics? $\mathrm{v}=$ full-content. Accessed October 4, 2018.
13. The National Coalition of Economic Social and Cultural Rights, Human Rights Network-Uganda (HURINET-U). The State of Implementation of Economic, Social, and Cultural Rights in Uganda.; 2015. www.hurinet.or.ug. Accessed October 4, 2018.

14. Marschark M, Shaver DM, Nagle KM, Newman LA. Predicting the Academic Achievement of Deaf and Hard-of-Hearing Students From Individual, Household, Communication, and Educational Factors. Except Child. 2015;81(3):350-369. doi:10.1177/0014402914563700.

15. Patrikakou EN. The Power of Parent Involvement: Evidence, Ideas, and Tools for Student Success.; 2008. www.centerii.org. Accessed October 4, 2018.

16. Mugeree A, Atekyereza PR, Kirumira EK, Hojer S. Deaf identities in a multicultural setting: The Ugandan Context. African J Disabil. 2015;4(1):9. https://ajod.org/ index.php/ajod/article/view/69/305. Accessed October 4, 2018.

17. Anderson LM, Shinn C, Fullilove MT, et al. The effectiveness of early childhood development programs. A systematic review. Am J Prev Med. 2003;24(3 Suppl):32-46. http://www.ncbi.nlm.nih.gov/pubmed/12668197. Accessed October 4, 2018.

18. Landry SH. Parenting skills: Role of parents in early childhood learning | Encyclopedia on Early Childhood Development. In: Tremblay R, Boivin M, Peters Rd, eds. Encyclopedia on Early Childhood Development. ; 2014. http://www.child-encyclopedia.com/parenting-skills / according-experts / role-parents-early-childhood-learning. Accessed October 4, 2018.

19. WHO. CHILDHOOD HEARING LOSS.; 2016. http://www.who.int/pbd/deafness/world-hearing-day/ WHD2016_Brochure_EN_2.pdf. Accessed October 4, 2018.

20. El Nokali NE, Bachman HJ, Votruba-Drzal E. Parent Involvement and Children's Academic and Social Development in Elementary School. Child Dev. 2010;81(3):9881005. doi:10.1111/j.1467-8624.2010.01447.x.

21. Smith R, Shearer A, Hildebrand M, Van Camp G. Deafness and Hereditary Hearing Loss Overview. 2012. http:/ /0-www.ncbi.nlm.nih.gov.innopac.lsuhsc.edu/ books/NBK1434/?report=printable. Accessed October 4, 2018.

22. Roberts SO. The Relationship between Parental Involvement and Mathematics Achievement in Struggling 
Mathematics Learners. NYU Appl Psychol Opus. 2011. doi:10.1080/01443410903353302.

23. Harris M, Terlektsi E. Reading and Spelling Abilities of Deaf Adolescents With Cochlear Implants and Hearing Aids. J Deaf Stud Deaf Educ. 2011;16(1):24-34. doi:10.1093/deafed/enq031.

24. Mpofu J, Chimhenga S. No TitleChallenges faced by Hearing Impaired Pupils in Learning: A Case Study of King George VI Memorial School. J Res Method Educ. 2013;2(1):69-74.

25. Farooq M, Chaudhry A, Shafiq M, Berhanu G. Factors affecting students' quality of academic performance: A case of secondary school level. J Qual Technol Manag. 2011;(2):1-14. https://www.researchgate.net/publication/284150574_Factors_affecting_students'_quality_of_academic_performance_A_case_of_secondary_ school_level.

26. Reche GN, Triphosa M, Bundi K, Justus M, Riungu N, Kariuki Mbugua Z. Factors Contributing to Poor Performance in Kenya certificate of primary education in public day primary schools in Mwimbi Division, Maara District, Kenya. Int J Humanit Soc Sci. 2012;(5):127-133. www.ijhssnet.com. Accessed October 4, 2018.

27. Etsey K. Assessing Performance in Schools: Issues and Practice. IFE Psychol. 2005;13(1):123-135. doi:10.4314/ ifep.v13i1.23665.

28. Braswell-Burris PA. Factors Affecting the Educational and Personal Success of Deaf or Hard of Hearing Individuals. 2010. http://sdsu-dspace.calstate.edu/bitstream/handle/10211.10/359/Braswell-Burris_Patrice. pdf;sequence=1. Accessed October 4, 2018.

29. Chowa GAN, Masa RD, Tucker J. The effects of parental involvement on academic performance of Ghanaian youth: Testing measurement and relationships using structural equation modeling. Child Youth Serv Rev. 2013;35(12):2020-2030. doi:10.1016/j. childyouth.2013.09.009.

30. Epstein JK, Coates L, Salinas K, Sanders M, Simon B. Epstein's Framework of Six Types of Involvement. 2005. https://www.sps186.org/downloads/table/13040/ 6TypesJ. Epstien. pdf. Accessed October 4, 2018.

31. Gonzalez-Dehass AR, Willems PP. Examining the Underutilization of Parent Involvement in the Schools. Sch Community J. 2003;13(1):85-99. http://www.adi.org/ journal/ss03/gonzalez-dehass \& willems.pdf. Accessed October 4, 2018.

32. Reed S, Antia SD, Kreimeyer KH. Academic status of deaf and hard-of-hearing students in public schools: student, home, and service facilitators and detractors. $J$ Deaf Stud Deaf Educ. 2008;13(4):485-502. doi:10.1093/ deafed/enn006.

33. Antia SD, Jones PB, Reed S, Kreimeyer KH. Academic Status and Progress of Deaf and Hard-of-Hearing Students in General Education Classrooms. J Deaf Stud Deaf Educ. 2009;14(3):293-311. doi:10.1093/deafed/enp009.

34. Zand DH, Pierce K. Resilience in Deaf Children. (Zand DH, Pierce KJ, eds.). New York, NY: Springer New York; 2011. doi:10.1007/978-1-4419-7796-0.

35. Agyire-Tettey EE, Cobbina M, Hamenoo ES. Academic Challenges of Students with Hearing Impairment (SHIs) in Ghana. Disabil CBR Incl Dev. 2017;28(3):127150. doi:10.5463/dcid.v28i3.646.

36. El-Zraigat IA, Smadi Y. Challenges of Educating Students Who Are Deaf and Hard-Of-Hearing in Jordan. Vol 2.; 2012. www.ijhssnet.com. Accessed October 4, 2018.

37. Wilkinson G. Wide Range Achievement Test: WRAT3. 1993. https://www.unc.edu/depts/sph/longscan/ pages/measures/Ages12to14/writeups/Age 12 WRAT3.pdf. Accessed October 4, 2018.

38. Wright T. Parent and Teacher Perceptions of Effective Parental Involvement. Dr Diss Proj. May 2009. https:// digitalcommons.liberty.edu/doctoral/198. Accessed October 4, 2018.

39. Price-Mitchell M. Book Review Book Review of School, Family, and Community Partnerships: Preparing Educators and Improving Schools. Vol 21.; 2011. http:/ /www. adi.org/journal/2011ss/Price-MitchellSpring2011.pdf. Accessed October 11, 2018.

40. Mediterranean Center of Social and Educational Research. E, Wadesango N, Hove E, Gudyanga A. Mediterranean Journal of Social Sciences. Vol 5. MCSER; 2014. http://www.mcser.org/journal/index.php/mjss/article/ view/2657. Accessed October 4, 2018.

41. Joy Caño K, Grace Cape M, Mar Cardosa J, Miot C, Rianne Pitogo G, Mae Quinio Jewish Merin C. Parental Involment on Pupils' Performance: Epstein's Framework. Online. J New Horizons Educ. 2016;6(4). www.tojned.net. Accessed October 4, 2018.

42. Shaw CA. A Study of the Relationship of Parental Involvement to Student Achievement in a Pennsylvania Career and Technology Center. 2007. https:/ / etda.libraries.psu.edu/catalog/8742. Accessed October 4, 2018. 43. Bagenda D, Nassali A, Kalyesubula I, et al. Health, neu- 
rologic, and cognitive status of HIV-infected, long-surviving, and antiretroviral-naive Ugandan children. Pediatrics. 2006;117(3):729-740. doi:10.1542/peds.2004-2699.

44. Bangirana P, Musisi S, Boivin MJ, et al. Malaria with neurological involvement in Ugandan children: effect on cognitive ability, academic achievement and behaviour. Malar J. 2011;10:334. doi:10.1186/1475-2875-10-334.

45. Jastak J, Wilkenson G. Wide Range Achievement Test-Third Edition (WRAT-3). Designed to assess the congitive ability of children. 1993.

46. Toscano RM, McKee B, Lepoutre D. Success with academic English: reflections of deaf college students. Am Ann Deaf. 2002;147(1):5-23. http://www.ncbi.nlm.nih. gov/pubmed/12061192. Accessed October 4, 2018.

47. Vukovic RK, Roberts SO, Green Wright L. ARTICLES From Parental Involvement to Children's Mathematical Performance: The Role of Mathematics Anxiety. 2013. doi:10.1080/10409289.2012.693430.

48. Bandura A. SOCIAL COGNITIVE THEORY: An Agentic Perspective. 2000. https://courseplus.jhu.edu/ fileDepot/onlineLibrary/674/C06_H1_ABandura_AnnRevPsych_2001.pdf. Accessed December 10, 2017.

49. Falk A, Fischbacher U. A theory of reciprocity. Games Econ Behav. 2006;54(2):293-315. doi:10.1016/J. GEB.2005.03.001.
50. Koontz H, O’Donnell C, Weihrich H. Management. 8th ed. New York: McGraw-Hill; 1984. https://catalyst. library.jhu.edu/catalog/bib_570245. Accessed October 4, 2018.

51. Kelly Y, Sacker A, Del Bono E, Francesconi M, Marmot M. What role for the home learning environment and parenting in reducing the socioeconomic gradient in child development? Findings from the Millennium Cohort Study. Arch Dis Child. 2011;96(9):832-837. doi:10.1136/ adc.2010.195917.

52. Epstein J. School/Family/Community Partnerships: Caring for the Children We Share., Phi Delta Kappan, 1995. Phi Delta Kappan. 1995;76(9):701-712. https://eric. ed.gov/?id=EJ502937. Accessed October 4, 2018.

53. Musonda N, Phiri W. Emerging Factors Affecting Academic Performance of Learners with Hearing Impairments at Grate Twelve Examination Level 2017. Int J Multidiscip Res. 2017.

54. Desforges C, Abouchaar A. The Impact of Parental Involvement, Parental Support and Family Education on Pupil Achievements and Adjustment: A Literature Review RESEARCH. https://www.nationalnumeracy.org. uk/sites/default/files/the_impact_of_parental_involvement.pdf. Accessed October 4, 2018. 